УДК 94(470.325):656.2

DOI 10.18413/2075-4458-2019-46-3-516-524

«МНЕ В ЖИЗНИ НЕ НА КОГО БЫЛО НАДЕЯТЬСЯ, НЕ ПЕРЕД КЕМ "НЕЖИТЬСЯ”»: ЖЕНЩИНЫ-ЖЕЛЕЗНОДОРОЖНИЩЫ В УСЛОВИЯХ РАЗМЫВАНИЯ ТРАДИЦИОННЫХ ГЕНДЕРНЫХ РОЛЕЙ В ДЕЛЕ МАТЕРИАЛЬНОГО ОБЕСПЕЧЕНИЯ СЕМЬИ В КОНЦЕ 1960-Х - 1980-Х ГГ.

\title{
«I WON'T BACK ON ANYONE IN MY LIFE, THERE WAS NO ONE TO "LAZE" MYSELF TO»: WOMEN-RAILWAYS UNDER CONDITIONS OF WASHING OUT TRADITIONAL GENDER ROLES IN THE MATERIAL SUPPORT OF THE FAMILY IN THE END OF THE 1960s - 1980s.
}

\section{Е.Н. Меньшикова E.N. Menshikova}

\author{
Белгородский государственный национальный исследовательский университет, \\ Россия, 308015, г. Белгород, ул. Победы, 85 \\ Belgorod National Research University, \\ 85 Pobeda St, Belgorod, 308015, Russia \\ E-mail: menshikova@bsu.edu.ru
}

\begin{abstract}
Аннотация
В статье на основе исследования устных воспоминаний (истории профессиональных и жизненных стратегий) женщин-железнодорожниц, сотрудниц службы управления движением поездов Белгородского отделения Южной железной дороги Министерства путей сообщения СССР (курский и старооскольский участки: станции Белгород-Клюква, Сараевка-I - Сараевка-II-Старый Оскол): поездных диспетчеров, дежурных по станции (ДСП), операторов при ДСП - «движенцев», важнейших фигур на железнодорожном транспорте, рассмотрены некоторые проявления (в семейном укладе) трансформации их гендерной идентичности, происходившей под влиянием специфики профессиональной занятости («экстремальная) рабочая повседневность).Факторами этого являлись: «командирский» характер работы женщин - сотрудниц службы движения, которые осуществляли единоначальное руководство организацией движения поездов в пределах станции, относительно высокий уровень заработной платы и материального обеспечения, а также возможность приобретения дефицитных товаров и продуктов у машинистов и проводников скорых поездов, курсировавших между Москвой и Харьковом. В этой связи роль женщин «Движенцев» в материальном обеспечении семьи оказывалась сопоставимой (или даже была выше) с другими членами (родители, муж, взрослые дети).
\end{abstract}

\footnotetext{
Abstract

The article is based on a study of oral memories (history of professional and life strategies) of female railway workers, employees of the train traffic control service of Belgorod branch of the Southern Railway of the USSR Ministry of Railways (Kursk and Stary Oskol sites: Belgorod - Klukva station, Saraevka-I - Saraevka-II - Stary Oskol). They were the most important figures in the railway transport, the train dispatchers, station attendants, operators-〈(movers». The author considers some manifestations (in the form of the family) of the transformation of their gender identity, which occurred under the influence of the specifics of professional employment ("extreme" working everyday life). The main factors of transformation of their gender identity are revealed: the "commanding» nature of the work of women - employees of the traffic service, who exercised the sole leadership of the organization of train movement within the station, the relatively high level of wages and material support, and the possibility of purchasing scarce goods and products from drivers and high-speed train conductors, plying between Moscow and Kharkov. In this regard, the role of women - «movers» in the material security of the family turned out to be comparable (or even higher) with other members (parents, husband, adult children).
} 
Ключевые слова: женская история, устная история, гендерная идентичность, женщины-железнодорожницы, служба управления движением поездов, СССР, 1960-1980-е годы. Key words: women's history, oral history, gender identity, women railway workers, train control service, USSR, 1960-1980s.

Представляемая в настоящей статье проблема является частью исследовательского проекта «Женщины в системе управления движением железнодорожного транспорта в СССР в 1970-е - начале 1990-х гг.: профессия и установление гендерного равенства (по материалам Белгородского отделения Южной железной дороги МПС СССР)» ${ }^{1}$. В результате поисковой работы к апрелю 2019 г. установлены персоналии (и восстановлен хронотоп их профессиональной деятельности) ста пяти женщин-железнодорожниц - сотрудниц службы управления движением поездов Белгородского отделения Южной железной дороги Министерства путей сообщения СССР (курский и старооскольский участки: станции Белгород - Клюква, Сараевка-I - Сараевка-II - Старый Оскол): поездных диспетчеров, дежурных по станции (ДСП), операторов при ДСП - «движенцев», работавших в конце 1960-х гг. - 1980-х гг. [Голубенко, 1962; Рыскин, 1963; Почепской, 1967; Кусакина, 1973а, Кусакина, 1973b, Ковалев, 1974; Зозуля, 1976; Кусакина, 1977; Фото... , 1979; Ковалев и др., 1980; Кусакина, 1982а, Кусакина, 1982b; Руду..., 1982; Кусакина, 1983; Коренев и др., 1984; Рожок, 1984; Владимиров, 1988; Точки..., 1991; Пшеничных, 2018].

Это - поездные диспетчера (ДНЦ, г. Белгород): Анпилова М.А., Горбунова А.Н., Ефимова М.И., Мазненко С.Ф., Соломатина В.И., Пыханова 3.Г., Байбикова Л.В., Марченко С., Солдатенко Г.В., Меньшикова В.А., Павлова (Березанец) Е.В., Тарасова С.А., Тарараева С.Ф., Степанова А.К.; ревизор движения (ДНЧ) участка Ржава - Сараевка-ІІ Клюква, Ржава - Обоянь - О.И. Добродумова; дежурные по станции (ДСП): станция Белгород (Шаталова Н.А., Дудченко Л.П., Гударева В.М., Беликова Р.Я., Лысенко Л.Л., Клавкина Н.Н.); станция Гостищево (Колесникова М.В., Кизилова В., Романовская А.); станция Сажное (Чавыкина М.И., Беликова А.И.); станция Прохоровка (Курганская Л., Кулабухова В.П.); станция Шебекино (Морозова Е.А.); станция Ржава (Бабынина Л.И., Дорохова Р.В., Бочарова Л.П., Багрова Г.Н., Риштакова А., Клименко Р.И.); станция Сараевка-I (Чала (Лобова) М.К., Мажара Н., Кравченко Л., Рыбалко Н., Лобова Т., Новикова О., Меньшикова А.Е., Новикова Н.Н., Надеина В.П., Шаталова В.А., Баландина Т.В., Строганова Л.И.); станция Сараевка-ІІ (дежурные по станции: Надеина Р.П., Надеина Е., Баландина Т.В., Баландина А.И., Гуреева Н.Д., Позднякова Н.П., Бочарова Н.Е., Заводнова Н.П., Заводнова Г.И., Морозова В.И., Надеина Н.И.; операторы при ДСП (Меньшикова З.В., Ершова К.М.); приемосдатчики (Белозерова А.П., Прозорова 3.К., Прозорова Н.П.); сигналисты (Ширяева Л.И., Солдатенко В.И., Бойдинова Т.А., Дагаева Л.В., Петренкова Л.М., Богачева Н.В., Заводнова К.С.); станция Сазановка (Бельчикова Л.П., Фурсова В.И., Сошенкова М.П., Позднякова Н.П.); станция Кривецкая (Болотникова Р.Н., Рябцева К., Реброва В., Зайцева Л.В., Сафронова Р.Н., Суслова Е.); станция Чаплыжная (Савина В.); станция Губкин (Домарева Т.В.); станция Стойленская (Л.А. Гончарова); станция Старый Оскол (Самойлова Г.Н., Анпилова М.А.); станция Солнцево (Федорова М.П., Филатова Е.П., Дорохова (Михеева) Н.Н., Васюкова Г.В., Бочарова Л.А., Пархоменко Л.А., Коваль С.В., Пономарева Г.); станция Шумаково (Воробьева Т., Бобнева Л.); станция Полевая (Печенева Т., Пачковская М., Крамская Т., Рыжкова Т.); станция Конарево (Гуторова Г., Заикина Т., Глебова Т., Конорева Е.И., Орлова А.И.); станция Клюква (Михайлова В.).

Подобная персонификация объектов исторического исследования соответствует «формату» женской и гендерной истории, направлению в отечественной исторической науке (возглавляемому Н.Л. Пушкаревой [Пушкарева, 1998]), для которого актуально «открытие» новых героинь - обычных (в традиционном понимании) женщин, чей жизненный

1 Проект № 19-09-00359/19, поддержанный Российским фондом фундаментальных исследований (РФФИ). 
и профессиональный путь являет собой пример «повседневного героизма». А женщиныжелезнодорожницы из сферы «движения) перманентно демонстрировали его в рамках выполнения служебных обязанностей. Их успешная реализация требовала от женщин не только хороших профессиональных знаний, но и особых психо-физиологических качеств (работа требовала сверхконцентрации внимания в течение двенадцатичасового дежурства, выносливости, отличалась высоким уровнем стресса), связанных с тем, что они единолично (в дневные и ночные смены) осуществляли распоряжение организацией движения поездов в пределах станции или участка (диспетчерского круга) [Буканов, 1987, с. 5; Инструкция..., 1989, с. 5; Гусаков, 2003; Ковалев, 2015]. Необходимо отметить, что ни в какой другой сфере экономики СССР не сложились условия для подобной - ярко выраженной и хорошо маркируемой - трансформации гендерной (женской) идентичности; формирования новой модели гендерного взаимодействия - гендерного равенства [История..., 2004]. Устные нарративы женщин-железнодорожниц позволяют проследить проявления вышеобозначенных явлений и вне профессиональной сферы, в особенностях организации их семейного уклада.

Метафорическое утверждение о «железном» характере женщин-железнодорожниц вообще, и особенно женщин-«движенцев», в том или ином виде свойственно устным воспоминаниям всех опрошенных в ходе настоящего исследования женщин-ветеранов Белгородского отделения ЮЖД [Бабынина, 2019; Баландина, 2019; Бойдинова, 2019; Бочарова, 2019; Дагаева, 2019; Строганова, 2019; Ширяева, 2019]. Однако выяснить, насколько быстро (со времени начала работы) подобная гендерно-стереотипная характеристика становилась индивидуально осознаваемой женщинами-железнодорожницами и ментально принятой (верили ли они в это или хотели верить, чтобы не бояться быть «не железной»), а не поверхностно усвоенной и внешне артикулируемой лишь для получения социального одобрения в профессиональной, преимущественно мужской среде, представляется довольно сложным. Вместе с тем в воспоминаниях зафиксированы ярко выраженные маркеры изменения традиционных гендерных «правил» в стиле поведения женщинжелезнодорожниц вне служебной деятельности, произошедших под ее непосредственным влиянием.

Эти изменения касаются приобретения неких маскулинных («железных») черт в женском поведении, в их числе считающаяся одной из главных в разрушении традиционного гендерного порядка [Берн, 2002] - осознание себя как основного (или по меньшей мере не комплементарного по вкладу в семейный бюджет) «добытчика» в семье (дежурная по станции Сараевка-I Л.И. Строгонова (стаж работы на железнодорожном транспорте 28 лет): «А я всех всегда обеспечивала и была, как в поговорке: "я-и лошадь, я-и бык, яи баба, и мужик"» [Строгонова, 2019]; дежурная по станции Сараевка-I А.Е. Меньшикова (стаж работы на железнодорожном транспорте 39 лет): «Мне в жизни не на кого было надеяться, не перед кем "нежиться". Мой муж, на равных со мной, работал на транспорте, в смене» [Меньшикова, 2019]; начальник станции Сараевка-II В.И. Морозова (стаж работы на железнодорожном транспорте 38 лет): «Я всю жизнь всех их (о членах семьи Е.М.) одна тянула) [Морозова, 2019]; дежурная по станциям Сараевка-II, Кривецкая Н.Е. Бочарова, стаж работы на железнодорожном транспорте 30 лет: «Я никогда не рассчитывала на мужчин. Помла работать с семнадиати лет. Да я и замуж не собиралась» [Бочарова, 2019]; начальник станции Солнцево Г.В. Васюкова, стаж работы на железнодорожном транспорте 39 лет: «После безвремениой смерти мужа, а мие было тогда всего сорок два года, у меня не стало никакой защиты. Я одна должна была заботиться о своих сыновьяху) [Васюкова, 2019].

Надо заметить, подобные женские оценки себя - часто жесткие и мезоандринные по сути - как главных фигур в обеспечении семей все же следует принимать с некоторой осторожностью, поскольку они являются односторонними (не учтены воспоминания членов семей железнодорожниц, в том числе и их мужей) и, возможно, преувеличенными, сконструированными искусственно в силу принятого в железнодорожной среде подчерки- 
вания в людях, в женщинах того самого «железного» характера. Эти оценки поддерживались относительно высокими заработками женщин (по сравнению, скажем, с занятыми в колхозной экономике, доминирующей в исследуемый период на изучаемой территории), отсюда - их независимым материальным статусом (Строганова Л.И.: «Я пошла на железную дорогу из медицины за больиими деньгами. В больнице мне, медсестре, платили тогда 60 рублей. А дежурной стала получать 120. Есть разница?» [Строгонова, 2019]; дежурная по станции Солнцево Н.Н. Михеева (стаж работы на железнодорожном транспорте 36 лет): «Ой, мы тогда были просто миллионерами. Хлеб-то ведь стоил 16 копеек. Поедешь в Курск, наберешь на рубль иесть буханок хлеба и “еиь - не хочу”. Мы чувствовали тогда себл очень богатыми. Нам ведь и премии давали. Небольиие, конечно, рублей по десять-пятнадчать. О них и в трудовой книжке писали. И “ночные", и "праздничные" (дежурства - Е.М.) оплачивали вдвойне. А потом, в конце года, и "тринадчатую" зарплату платили. Правда, потом, ее отменили» [Михеева, 2019]). А также - условиями жизни семей железнодорожников в реальности тотального дефицита продуктов и непродовольственных товаров в системе снабжения на железнодорожных станциях в исследуемый период и теми «предпринимательскими» усилиями, которые прилагали женщиныжелезнодорожницы для приобретения товаров, необходимых семьям.

Для «доставания» недоступных в свободной продаже продуктов, одежды и обуви, бытовых предметов женщины-«движенцы» использовали разные возможности, предоставляемые работой на железной дороге, в том числе бесплатный проезд в пригородных и дальнего следования поездах для поездок в города с развитой торговой инфраструктурой: Губкин, Курск, Белгород, Харьков, Москву и др. (Бочарова Н.Е.: « Мы же с каждого аванса в Губкин ездили за продуктами. Здесь же (в Курской области - Е.М.) ничего не было. Ну совсем ничего. А там... Ну там же болгары были (строители - Е.М). Для пих-то старались. Снабжсли их лучие. Мы брали с собой все сорок рублей аванса и везли домой четьре сумки: две в руках, а две свяжешь платком и на плечо - “наперевес". На месяи еды хватало. Там такая сметана была! По две трехлитровых банки брали. А котлеты в кулинарии... Я брала их по сто итук, а стоили всего пять копеек. И как мы тащили на своих плечах столько?! Молодые были... Только "рублевой" колбасы я покупала по десять килограммов) [Бочарова, 2019]; Морозова В.И. «Мы часто в Москву с “отпускными” ездили. Везли все: и хлеб, и масло сливочное, и колбасу, и селедку. Ох, какал же там была селедка! В мою ладонь иириной. И одежду, конечно, везли. Я там болгарский костюм купила, пляжный, и югославские сапоги. А еще сумку кожаную, импортную. Накупили столько, что, казалось, иелый вагон выгружаем» [Морозова, 2019]; Михеева Н.Н.: «На "оперативку" (оперативное совещание в Управление ЮЖД - Е.М.) едешь, бывало, в Харьков, девчата все со станции обычно заказывали купить харьковского круглого хлеба и колбасы. Я же училась там, в техникуме, в Харькове, все гастрономы знала. Какие там колбаснье отделы были! Какое изобилие! Люди в очереди от аромата сознание теряли! На нас горожане смотрели как на варваров. Мы же мешками колбасу-то эту скупали. А как же? На всех же на станиии везли! И копченую, и особенно вареную брали. "Докторскую” двухкилограммовыли котелками брали!» [Михеева, 2019], Меньшикова А.Е.: «Мы приехали в Киев в 80-м году, в воскресенье, а там у них, в отличие от нас, в воскресенье магазины не работают. Мы походили-походили, да и обратно - на вокзал. Там один какой-то магазин только и работал. Купили ковры там безворсовые, у нас таких тут не было в продаже. А ече купили по десять метров набивного ситиа с изображением символики Олимпиады-80. Мне мама моя потом сарафан из него сиила» [Меньшикова, 2019]. «Каналами» поставки дефицитных товаров для героинь настоящей статьи были и профессиональные контакты с машинистами и проводниками скорых поездов. Последние, в отличие от первых, занимались «мелкооптовой торговлей». Опрошенные женщиныжелезнодорожницы вспоминали, как практически каждая из них за годы работы пользовалась помошью машинистов поездов дальнего следования, которых можно было попросить привезти (главным образом из Харькова) необходимые продукты. «Фаворитами» среди 
товаров назывались колбасные изделия и харьковский хлеб [Бабынина, 2019; Меньшикова, 2019; Морозова, 2019; Михеева, 2019; Надеина, 2019; Новикова, 2019] («Я - “в день” (в дневную смену, с 08.00 до 20.00 часов - Е.М.). Забегает в “дежурку” Малов (Малов А.С., машинист из Харьковского депо - Е.М.). У него же здесь теща жила. Спрашивает: "Что в следуюиий раз привезти?". Я даю деньги и заказываю сосисок килограммов на пять» - Меньшикова А.Е. [Меньшикова, 2019]; «Mbl часто колбасу и сосиски маиинистам харьковским заказывали. Бывало, едут и вызывают по рачии: «Натаика, выходи, лови свою колбасу!». Вот смеху-то было. Летят на ходу поезда пакеты с колбасой» Михеева Н.Н. [Михеева, 2019]).

Проводники скорых поездов, идущих на Москву, принимали у женщин-движенцев «заказы» на доставку московских товаров: в летний сезон домашней консервации овощей и фруктов - металлических крышек для стеклянных банок; в сезон летних отпусков - бумажных обоев для ремонта квартир; в предновогоднее время - мандаринов; круглогодично - продуктов питания (сливочного масла, кофе, конфет), предметов постельного и столового белья; в отдельных случаях - предметов детской одежды (особенно для новорожденных). На практике «покупка» у проводников дефицитных товаров происходила стремительно - во время минутной стоянки скорого поезда на станциях. Проводников поездов, следовавших в Крым, женщины-железнодорожницы в летнее время просили привезти южных фруктов, редких в то время для средней полосы России, - персиков и абрикосов.

Еще одним способом приобретения дефицитных продуктов в 1970-1980-е гг. была их покупка у железнодорожных агентов, сопровождавших грузы в рефрижераторных вагонах (Меньшикова А.Е.: «Однажды мы купили в “рефрижераторе” иелый таз, в котором ноги моют, зеленых, неспельх бананов. Это было где-то в 78-м году. Мы прежде и не пробовали их. Невкусными показались. Все говорили: "Бананы!! Бананы!". А что в них такого особенного, и не поняли тогда...») [Меньшикова, 2019]; дежурная по станции Сараевка-І Н.Н. Новикова (стаж работы на железнодорожном транспорте 35 лет): «Мы тогда много разной рыбы морской в “рефрижераторах” покупали. Мать моя окуня морского любила очень есть» [Новикова, 2019]

Как видно, с одной стороны, такая детальная фиксация в памяти женщинжелезнодорожниц способов и сопровождавших их сложностей добывания продуктов питания в условиях дефицита, точное воспроизведение цен, вплоть до копеек, в целом отражает особенности женских устных нарративов при описании жизненных явлений [Пушкарева, 2001]. Это, на наш взгляд, свидетельствует также и о невысоком уровне притязаний советских людей в «консюмеризмском» отношении (привычка довольствоваться малым, оправдываемая советским стилем жизни). С другой стороны, в этих сюжетах воспоминаний железнодорожниц четко прослеживается выстроенный ими (надо думать, со временем) несколько утрированный конструкт образа независимой, «сильной» женщины, претендующей на гендерное равенство/женское лидерство в семейной сфере.

В целом в ходе исследования устных воспоминаний железнодорожниц из службы управления движением поездов, проработавших в данной структуре длительное время (принятой практикой была работа десятилетиями, в течение 30-40 лет), удалось «услышать» голос своего рода уходящей социально-культурной «натуры»- советской женщины «нового типа) с независимым экономическим и социальным статусом. Распространение профессионального статуса на социальный было связано с рядом причин: во-первых, в рассматриваемый период происходила феминизация службы движения: женщины выполняли те же обязанности, что и мужчины, их численность неуклонно росла. Более того, специфика работы специалистов службы движения заключалась в организации движения поездов в пределах отдельной станции. И в процессе решения этой задачи им были подчинены сотрудники всех служб, задействованных на конкретной станции. То есть женщины-«движенцы»на абсолютно легитимных основаниях осуществляли руководство мужчинами - сотрудниками остальных служб, которые были обязаны им беспрекословно подчиняться. Во-вторых, в рассматриваемый период уровень заработной платы и комплекс 
льгот у женщин-«движенцев» позволял им ощущать свою материальную независимость от остальных членов семьи (родители, муж). В-третьих, в силу специфики своей профессиональной деятельности они, больше чем кто-либо из железнодорожников, были включены в коммуникативные практики советской «теневой» экономики, связанные с возможностью приобретения дефицитных продуктов и товаров. Маршруты скоростных поездов связывали Москву и Харьков, а пригородных - Курск и Белгород. Интенсивность движения на участках Белгородского отделения Южной железной дороги составляла десятьодиннадцать поездов в час. И в этой ситуации дежурные по станции, диспетчера имели уникальную возможность, не выезжая за пределы станции, приобрести необходимые продукты и товары.

Следствием этих обстоятельств стала трансформация их гендерной идентичности. По сути, профессиональная деятельность железнодорожниц, позволявшая им на паритетных началах принимать участие в материальном обеспечении семьи или даже вносить больший вклад, способствовала складыванию в их среде новой модели взаимодействия с мужчинами - гендерного равенства.

\section{Благодарности}

Исследование выполнено при поддержке Российского фонда фундаментальных исследований (РФФИ), проект № 19-09-00359/19

\section{Список литературы}

1. Бабынина Л.И. 2019. Воспоминания. Записала Е.Н. Меньшикова 10.03.2019. Белгород, 5 с. комп. набор.

2. Баландина А.И. 2019. Воспоминания [Memoirs]. Записала Е.Н. Меньшикова 10.04.2019. Белгород, 5 с. комп. набор.

3. Берн Ш. 2002. Гендерная психология. СПб., Нева, М., Олма-Пресс, 320.

4. Бойдинова Т.А. 2019. Воспоминания. Записала Е.Н. Меньшикова 12.03.2019. Белгород, 6 с. комп. набор.

5. Бочарова Н.Е. 2019. Воспоминания. Записала Е.Н. Меньшикова 21.03.2019. Белгород, 9 с. комп. набор.

6. Буканов М.А. 1987. Справочник дежурного по станции. М., Транспорт, 239.

7. Васюкова Г.В. 2019. Воспоминания. Записала Е.Н. Меньшикова 19.03.2019. Белгород, 10 с. комп. набор.

8. Владимиров В. 1988. Дороги железные, проблемы - известные (о дежурной по станции Прохоровка В. П. Кулабуховой). Коммунист. 18 октября: 3.

9. Голубенкко В. 1962. Наш командир (о маневровом диспетчере Старооскольского железнодорожного узла М.А. Анпиловой). Белгородская правда. 8 марта: 3 .

10. Гусаков Г.Н. 2003. Воспоминания начальника станции. Дно. URL: http://www.pskovrail.ru/novosti/vospominaniia_natschalinika_stanzii_7.html (дата обращения: 15.02.2019).

11. Дагаева Л.В. 2019. Воспоминания. Записала Е.Н. Меньшикова 14.04.2019. Белгород, 5 с. комп. набор.

12. Зозуля С. 1976. Решали секунды (о дежурной по станции Прохоровка Л. Курганской). Комсомольская правда. 22 мая: 3.

13. Инструкция по движению поездов и маневренной работе на железных дорогах СССР (утверждена 31.07.1979). 1989. М., ТЕХИНФОРМ, 317.

14. История железнодорожного транспорта Советского Союза. 2004. Т. 3. 1945-1991. гл. ред. Г.М. Фадеев. М., Академкнига. 631.

15. Ковалев В. 1974. Общественные организации коллектива (станция Белгород). Белгородская правда. 26 марта: 3 .

16. Ковалев В., Кусакина В. 1980. Скоростные рельсы. Белгородская правда. 11 февраля: 4.

17. Ковалев К.Е. 2015. Влияние нестандартных ситуаций на загруженность дежурных по станции. Вестник транспорта Поволжья. 1: 58-64.

18. Коренев В., Кусакина В. 1984. Поезда идут по графику. Белгородская правда. 4 апреля: 4. 
19. Кусакина В. 1973а. Плодотворное сотрудничество (о диспетчерах и машинистах). Белгородская правда. 27 июля: 4.

20. Кусакина В. 1973b. Расчет плюс творчество. Белгородская правда. 6 апреля: 4.

21. Кусакина В. 1977. Рейсы высокого качества. Белгородская правда. 3 августа: 4.

22. Кусакина В. 1982а. Конкурс диспетчеров (Белгородское отделение). Гудок. 23 мая: 3.

23. Кусакина В. 1982b. Новаторский почерк (о поездном диспетчере Белгородского отделения В. Соломатиной). Гудок. 5 сентября: 3.

24. Кусакина В. 1983. Эффект единой смены. Белгородская правда. 6 июня: 4.

25. Меньшикова А.Е. 2019. Воспоминания. Записала Е.Н. Меньшикова 11.03.2019. Белгород, 15 с. комп. набор.

26. Михеева Н.Н. 2019. Воспоминания. Записала Е.Н. Меньшикова 20.03.2019. Белгород, 16 с. комп. набор.

27. Морозова В.И. 2019. Воспоминания. Записала Е.Н. Меньшикова 16.03.2019. Белгород, 6 с. комп. набор.

28. Надеина В.П. 2019. Воспоминания. Записала Е.Н. Меньшикова 29.03.2019. Белгород, 5 с. комп. набор.

29. Новикова Н.Н. 2019. Воспоминания. Записала Е. Н. Меньшикова 17.03.2019. Белгород, 9 с. комп. набор.

30. Почепской М. 1967. На маленькой станции (коллектив станции Гостищево). Белгородская правда. 13 сентября: 2.

31. Пушкарева Н.Л. 1998. История женщин и гендерный подход к анализу прошлого в контексте проблем социальной истории. В кн.: Социальная история. 1997. Ежегодник. М., РОССПЭН: $69-95$

32. Пушкарева Н.Л. 2001. Андрогинна ли Мнемозина? (Гендерные особенности запоминания и исторической памяти). В кн.: Сотворение истории. Человек. Память. Текст. Науч. ред. Л.П. Репина, отв. ред. Е.А. Вишленкова. Казань, Мастер-лайн: 274-304.

33. Пшеничных Л. 2018. Береза у ее дома (о начальнике станции Солнцево Г. В. Васюковой). За честь хлебороба. 6 июля: 3.

34. Рожок В. 1984. Дочь солдата (об операторе центрального узла ЮЖД Т.В. Домаревой). Белгородская правда. 15 июня: 3. варя: 2 .

35. Руду, цемент, станки и сталь, неси, стальная магистраль! 1982. Октябрьские зори. 8 ян-

36. Рыскин К. 1963. Подруги (о диспетчерах Белгородского отделения А.Н. Горбуновой, М.И. Ефимовой, С.Ф. Мазненко). Белгородская правда. 12 января: 3.

37. Строганова Л.И. 2019. Воспоминания. Записала Е. Н. Меньшикова 12.03.2019. Белгород, 12 с. комп. набор.

38. Точки на карте Южной. На «маминой» станции (о начальнике станции Солнцево Г.В. Васюковой). 1991. Южная магистраль. 1 января: 2.

39. Фото дежурной по станции Белгород Н.А. Шаталовой - парторга коллектива. 1979. Гудок. 20 ноября: 3.

40. Ширяева Л.И. 2019. Воспоминания. Записала Е.Н. Меньшикова 25.03.2019. Белгород, 5 с. комп. набор.

\section{References}

1. Babynina L.I. 2019. Vospominaniya [Memoirs]. Zapisala E.N. Men'shikova 10.03.2019. Belgorod, $5 \mathrm{~s}$. komp. nabor.

2. Balandina A.I. 2019. Vospominaniya [Memoirs]. Zapisala E.N. Men'shikova 10.04.2019. Belgorod, $5 \mathrm{~s}$. komp. nabor.

3. Bern S.H. 2002. Gendernaya psihologiya. [Gender Psychology]. Saint Petersburg, Neva, Moscow, Olma-Press, 320.

4. Bojdinova T.A. 2019. Vospominaniya [Memoirs]. Zapisala E.N. Men'shikova 12.03.2019. Belgorod, 6 s. komp. nabor.

5. Bocharova N.E. 2019. Vospominaniya [Memoirs]. Zapisala E.N. Men'shikova 21.03.2019. Belgorod, 9 s. komp. nabor.

6. Bukanov M.A. 1987. Spravochnik dezhurnogo po stancii. [Directory attendant station]. Moscow, Transport, 239. 
7. Vasyukova G.V. 2019. Vospominaniya [Memoirs]. Zapisala E.N. Men'shikova 19.03.2019. Belgorod, $10 \mathrm{~s}$. komp. nabor.

8. Vladimirov V. 1988. Dorogi zheleznye, problemy - izvestnye (o dezhurnoj po stancii Prohorovka V. P. Kulabuhovoj). [The roads are iron, the problems are known (about the duty officer at the Prokhorovka station V. P. Kulabukhova)]. Kommunist. 18 oktyabrya: 3.

9. Golubenko V. 1962. Nash komandir (o manevrovom dispetchere Starooskol'skogo zheleznodorozhnogo uzla M.A. Anpilovoj). [Our commander (about the shunting dispatcher of the Starooskolsky railway junction M.A. Anpilova)]. Belgorodskaya pravda. 8 marta: 3 .

10. Gusakov G.N. 2003. Vospominaniya nachal'nika stancii. Dno. [Memories of the station master. Dno]. Available at: http://www.pskovrail.ru/novosti/vospominaniia_natschalinika_stanzii_7.html (accessed: 15.02.2019).

11. Dagaeva L.V. 2019. Vospominaniya [Memoirs]. Zapisala E.N. Men'shikova 14.04.2019. Belgorod, 5 s. komp. nabor.

12. Zozulya S. 1976. Reshali sekundy (o dezhurnoj po stancii Prohorovka L. Kurganskoj). [Solved the second (on duty on the station Prokhorovka L. Kurgan)]. Komsomol'skaya pravda. 22 maya: 3.

13. Instrukciya po dvizheniyu poezdov i manevrennoj rabote na zheleznyh dorogah SSSR (utverzhdena 31.07.1979) [Instructions on the movement of trains and maneuvering work on the railways of the USSR (approved 31.07.1979)] 1989. Moscow, Publ. TEKHINFORM, 317.

14. Istoriya zheleznodorozhnogo transporta Sovetskogo Soyuza [History of the Soviet Union railway transport]. 2004. T. 3. 1945-1991. gl. red. G.M. Fadeev. Moscow, Publ. Akademkniga. 631.

15. Kovalev V. 1974. Obshchestvennye organizacii kollektiva (stanciya Belgorod) [Public organizations of the collective (Belgorod station)]. Belgorodskaya pravda. 26 marta: 3.

16. Kovalev V., Kusakina V. 1980. Skorostnye rel'sy [Speed rails]. Belgorodskaya pravda. 11 fevralya: 4 .

17. Kovalev K.E. 2015. Vliyanie nestandartnyh situacij na zagruzhennost' dezhurnyh po stancii. [Influence of non-standard situations on the workload of station attendants]. Vestnik transporta Povolzhya. 1: 58-64.

18. Korenev V., Kusakina V. 1984. Poezda idut po grafiku [Trains go on schedule]. Belgorodskaya pravda. 4 aprelya: 4 .

19. Kusakina V. 1973a. Plodotvornoe sotrudnichestvo (o dispetcherah i mashinistah) [Fruitful cooperation (on dispatchers and machinists)]. Belgorodskaya pravda. 27 iyulya: 4.

20. Kusakina V. 1973b. Raschet plyus tvorchestvo [Calculation plus creativity]. Belgorodskaya pravda. 6 aprelya: 4 .

21. Kusakina V. 1977. Rejsy vysokogo kachestva [High quality flights]. Belgorodskaya pravda. 3 avgusta: 4 .

22. Kusakina V. 1982a. Konkurs dispetcherov (Belgorodskoe otdelenie) [Dispatcher Competition (Belgorod Branch)]. Gudok. 23 maya: 3.

23. Kusakina V. 1982b. Novatorskij pocherk (o poezdnom dispetchere Belgorodskogo otdeleniya V. Solomatinoj) [Innovative handwriting (about the train dispatcher of the Belgorod Branch V. Solomatina)]. Gudok. 5 sentyabrya: 3.

24. Kusakina V. 1983. Effekt edinoj smeny [The effect of a single shift]. Belgorodskaya pravda. 6 iyunya: 4 .

25. Men'shikova A.E. 2019. Vospominaniya [Memoirs]. Zapisala E.N. Men'shikova 11.03.2019. Belgorod, 15 s. komp. nabor.

26. Miheeva N.N. 2019. Vospominaniya [Memoirs]. Zapisala E.N. Men'shikova 20.03.2019. Belgorod, 16 s. komp. nabor.

27. Morozova V.I. 2019. Vospominaniya [Memoirs]. Zapisala E.N. Men'shikova 16.03.2019. Belgorod, 6 s. komp. nabor. (in Russian)

28. Nadeina V.P. 2019. Vospominaniya [Memoirs]. Zapisala E.N. Men'shikova 29.03.2019. Belgorod, 5 s. komp. nabor.

29. Novikova N.N. 2019. Vospominaniya [Memoirs]. Zapisala E. N. Men'shikova 17.03.2019. Belgorod, 9 s. komp. nabor.

30. Pochepskoj M. 1967. Na malen'koj stancii (kollektiv stancii Gostishchevo) [At a small station (the team Gostishchevo station)]. Belgorodskaya pravda. 13 sentyabrya: 2.

31. Pushkareva N.L. 1998. Istoriya zhenshchin i gendernyj podhod $\mathrm{k}$ analizu proshlogo $\mathrm{v}$ kontekste problem social'noj istorii. [The history of women and gender approach to the analysis of the past in the 
context of problems of social history]. V kn.: Social'naya istoriya [Social history]. 1997. Ezhegodnik. Moscow, Publ. ROSSPEHN: 69-95.

32. Pushkareva N.L. 2001. Androginna li Mnemozina? (Gendernye osobennosti zapominaniya i istoricheskoj pamyati). V kn.: Sotvorenie istorii. Chelovek. Pamyat'. Tekst [The creation of history. Person. Memory. Text]. Nauch. red. L.P. Repina, otv. red. E.A. Vishlenkova. Kazan, Publ. Master-Lain: 274-304.

33. Pshenichnyh L. 2018. Bereza u ee doma (o nachal'nike stancii Solncevo G.V. Vasyukovoj) [Birch near her house (about the head of the station Solntsevo G. V. Vasyukova)]. Za chest' hleboroba. 6 iyulya: 3

34. Rozhok V. 1984. Doch' soldata (ob operatore central'nogo uzla YUZHD T.V. Domarevoj) [The daughter of a soldier (about the operator of the central hub of the Southern Railway]. Belgorodskaya pravda. 15 iyunya: 3 .

35. Rudu, cement, stanki i stal', nesi, stal'naya magistral'! [Ore, cement, machine tools and steel, carry, steel line] 1982. Oktyabr'skie zori. 8 yanvarya: 2 .

36. Ryskin K. 1963. Podrugi (o dispetcherah Belgorodskogo otdeleniya A.N. Gorbunovoj, M.I. Efimovoj, S.F. Maznenko) [Girlfriends (about dispatchers of the Belgorod branch of A.N. Gorbunova, M.I. Efimova, S.F. Maznenko)]. Belgorodskaya pravda. 12 yanvarya: 3.

37. Stroganova L.I. 2019. Vospominaniya [Memoirs]. Zapisala E. N. Men'shikova 12.03.2019. Belgorod, 12 s. komp. nabor.

38. Tochki na karte Yuzhnoj. Na «maminoj» stancii (o nachal'nike stancii Solncevo G.V. Vasyukovoj) [Points on the map of South. At the "mother's" station (about the head of the station Solntsevo GV Vasyukova)]. 1991. Yuzhnaya magistral'. 1 yanvarya: 2.

39. Foto dezhurnoj po stancii Belgorod N.A. Shatalovoj - partorga kollektiva [Photo duty station at Belgorod N.A. Shatalova - party organizer of the team]. 1979. Gudok. 20 noyabrya: 3.

40. Shiryaeva L.I. 2019. Vospominaniya [Memoirs]. Zapisala E.N. Men'shikova 25.03.2019. Belgorod, 5 s. komp. nabor.

\section{Ссылка для цитирования статьи Reference to article}

Меньшикова Е.Н. «Мне в жизни не на кого было надеяться, не перед кем "нежиться"»): женщины-железнодорожницы в условиях размывания традиционных гендерных ролей в деле материального обеспечения семьи в конце 1960-х - 1980-х гг. Научные ведомости Белгородского государственного университета. Серия: История. Политология. 2019. Т. 46. № 3. С. 516-524. doi: 10.18413/2075-4458-2019-46-3-516-524

Menshikova E.N. (I won't back on anyone in my life, there was no one to "laze" oneself to»: women-railways under conditions of washing out traditional gender roles in the material support of the family in the end of the 1960s - 1980s. Belgorod State University Scientific Bulletin. History. Political Science. 2019. V 46. № 6. P. 516-524. doi: 10.18413/2075-4458-2019-46-3-516-524 